\title{
Evaluating the Economic Fairways for Hydrogen Production in Australia
}

\author{
Stuart D.C. Walsh ${ }^{\mathrm{a}, *}$, Laura Easton ${ }^{\mathrm{b}}$, Zhehan Weng ${ }^{\mathrm{a}}$, Changlong Wanga ${ }^{\mathrm{a}}$, \\ Joseph Moloney ${ }^{\mathrm{b}}$, Andrew Feitz ${ }^{\mathrm{b}}$ \\ ${ }^{a}$ Department of Civil Engineering, Monash University, Melbourne, Australia \\ ${ }^{b}$ Geoscience Australia, Canberra, Australia
}

\begin{abstract}
Assessments of hydrogen project viability typically focus on evaluating specific sites for development, or providing generic cost-estimates that are independent of location. In reality, the success of hydrogen projects will be intimately linked to the availability of local energy resources, access to key infrastructure and water supplies, and the distance to export ports and energy markets. In this paper, we present an economic model that incorporates assessments of these regional factors to identify areas of high economic potential for hydrogen production - the so-called "Economic Fairways" for such projects. In doing so, the model provides a tool that can be used to inform investors and policy makers on the available opportunities for hydrogen development and their infrastructure requirements. The model includes analysis of the regional economic potential for both blue and green hydrogen projects. It accounts for hydrogen production from renewable (wind and solar) sources, as well as non-renewable sources (steam-methane reformation and coal gasification) combined with carbon capture and storage. Results from case studies conducted with the tool are presented, illustrating the potential for hydrogen production across Australia.
\end{abstract}

Keywords: Economic Fairways, Green Hydrogen, Blue Hydrogen, Integrated Economic Assessment, Numerical Cost Modelling

\footnotetext{
*Corresponding Author

Email address: stuart.walsh@monash.edu (Stuart D.C. Walsh)
} 


\section{Introduction}

Australia, with its abundant natural resources and established energy export supply chains, appears well placed to participate in a new international hydrogen-energy market. Involvement in such a market promises a myriad of potential benefits: from reduced global CO2 emissions, in particular, from several sectors that have otherwise proven difficult to decarbonise (e.g. industrial heat, steel and cement production, heavy transport and large-scale machinery: Bataille et al., 2018; Kato and Kurosawa, 2019; National Hydrogen Strategy Taskforce, 2019a; Friedmann et al., 2019); to helping to stabilize electricity grids reliant on intermittent renewable-energy sources (GutiérrezMartín and Guerrero-Hernández, 2012; Bennoua et al., 2015; National Hydrogen Strategy Taskforce, 2019a); to increasing diversification and energy independence through the addition of a new fuel into the energy supply (US DOE, 2002; Ball and Wietschel, 2009; Ren et al., 2014; Scita et al., 2020). However, the unprecedented scale and complexity of this new industry calls for careful planning - requiring the creation of economic models and datasets capable of assisting policy makers and industry members to implement new hydrogen projects and supporting regional infrastructure (e.g. Bruce et al., 2018; ARUP, 2019).

To date, economic assessments of hydrogen project viability have largely concentrated on estimating the performance of individual projects or comparing the applicability of different technologies. Such analyses are either insensitive to location or primarily concerned with evaluating outcomes at specific sites. Nevertheless, at least initially, the success of hydrogen projects will be intimately linked to a conjunction of several geospatial factors. These include proximity to transportation infrastructure, distance to export ports, ready access to water, and the quality of the energy resource required to produce hydrogen (Feitz et al., 2019; ARUP, 2019). Thus, economic assessments of hydrogen project viability must also account for these factors when selecting appropriate development locations. Regions with a confluence of these features will have a greater likelihood of giving rise to hubs for hydrogen production, and should therefore be targets for investment to promote this industry.

In collaboration with Geoscience Australia, Monash University has developed an open-source software platform, known as Bluecap, to estimate the regional economic potential for resource development (Walsh et al., 2020; Haynes et al., 2020). Originally created to determine regional potential for 
mineral projects, the software platform has recently been extended to evaluate the economic potential for blue and green hydrogen. ${ }^{1}$ Output from the Bluecap code supports the Hydrogen Economic Fairways Tool hosted on Geoscience Australia's Hydrogen Opportunities portal (AusH2) (Geoscience Australia, 2021).

In this paper, we describe how the Bluecap software conducts its hydrogen project assessments. The hydrogen extension estimates the regional potential for the development of hydrogen projects across Australia by first creating a detailed model of hydrogen project value. The model is then applied to maps detailing the associated energy-resource distributions and infrastructure availability. In so doing, it identifies strategic areas of high economic potential for hydrogen production - the "Economic Fairways" of such projects. In the following sections, we outline the model used to evaluate hydrogen plant economics, and then describe how these calculations are extended to the regional scale. We also provide examples of case studies using the code to determine the potential for different classes of large-scale hydrogen projects.

\section{Economic Model}

The Bluecap code can be used to estimate the economic potential of a project either at a single location or over a prescribed region. A detailed description of the underlying software, in particular how it is applied to mineral projects, can be found in Walsh et al. (2020). This section gives an overview of how the economic analysis is extended to hydrogen projects.

Bluecap bases its predictions of economic potential on estimates of the after-tax Net Present Value (NPV) for a potential project. This is calculated by first assessing the energy required to support a hydrogen plant of a given annual output. Next, the required power plant capacity is determined based on the estimated capacity factor for the accompanying energy source at each location. From these estimates, the code then evaluates the infrastructure required to support the hydrogen plant and its power source: the water supply, the cost of transportation, and additional infrastructure to connect

\footnotetext{
${ }^{1}$ Here we define blue hydrogen as hydrogen production from non-renewable sources combined with carbon capture and storage (steam-methane reformation and coal gasification), whereas green hydrogen is defined as hydrogen production from renewable sources (presently limited to wind and solar in the Bluecap code).
} 
the plant to the electricity grid or to a carbon storage facility if required. The revenue from the plant and the associated startup and sustaining cost are then used to determine the before tax and after tax cash flows for the operation. An estimate of the after-tax NPV of the project is then found from these cash flows, and used to rank the relative potential for hydrogen project development. Key stages in this calculation are illustrated in Figure 1.

The Bluecap code allows the user to select between different development options for hydrogen projects. In particular, the user has several options for the means of hydrogen production and the associated power supply. Supported methods of hydrogen production include electrolysis from wind and solar (green hydrogen), as well as production from steam-methane reformation and coal gasification with carbon capture and storage (blue hydrogen). Default cost models are provided for each method of production. In particular, a number of different electrolysis cost models are included based on those given in the Bloomberg New Energy Frontier (Bloomberg New Energy Finance, 2020), as well as those reported in the CSIRO Hydrogen Roadmap (Bruce et al., 2018). The figures shown in this paper for renewable hydrogen were produced using cost models based on the BNEF estimates for electrolysis from established suppliers. The cost models associated with blue hydrogen production are provided based on the estimated costs provided in the CSIRO Hydrogen Roadmap (Bruce et al., 2018). These default models can be overridden by the user's own cost models as desired.

For steam-methane reformation and black- and brown-coal gasification, the power required for hydrogen production is assumed to be part of the process of hydrogen production. However, in the case of hydrogen produced by electrolysis, the user may select from different renewable sources of power for the power plant. At present three different categories of renewable power are supported by the model: wind power, photovoltaic solar power, and Concentrating Solar Power (CSP). In addition, the user can specify hybrid plants that combine wind and solar power sources.

By definition blue-hydrogen plants are assumed to operate in conjunction with carbon capture and storage. While the estimated costs of capture and storage are included in the original CSIRO-Roadmap, CO2-transmission costs are not (Bruce et al., 2018). Instead, the Bluecap model calculates these transmission costs based on the distance between the hydrogen plant location and the nearest potential storage reservoir. Likewise, steam-methane reformation projects must account for transmission costs from the nearest gas pipeline to the plant location, while coal gasification plants include the 


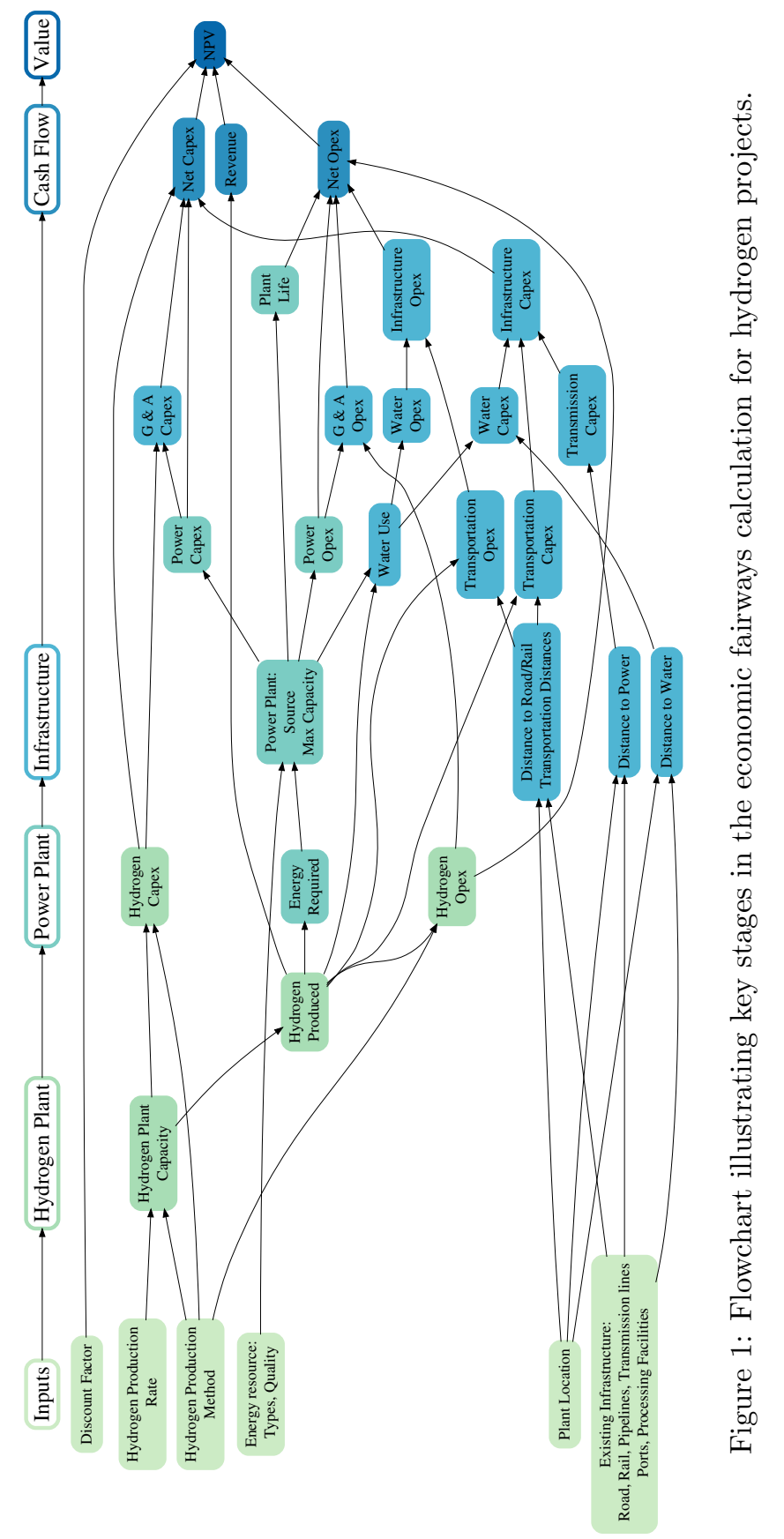


cost of coal transportation from the closest mine.

Capital and operating costs are determined for each of the renewable plants as a function of their scale and location. Cost estimates for the wind and photovoltaic plants are based on data gathered from feasibility studies, financial reports and company websites for Australian operations. Several key reports and their databases were used to establish the cost model for CSP. Specifically, Lovegrove et al. (2018) provide a comprehensive overview of Australia's CSP potential, while Hinkley et al. (2016), Bruce et al. (2018) and International Energy Agency (IEA) (2019) were used to validate several key assumptions such as cost factors, CSP and thermal storage system coefficient, location and sizing factor, land use, and water consumption.

Each plant requires additional infrastructure to operate. Transportation, water and even power transmission may be required depending on the nature of the plant. For example, all forms of hydrogen production require some form of water source, though the amount may vary depending on the water quality, the nature of the hydrogen plant and its associated power source. Transportation infrastructure, either road or rail, is needed to supply the construction material for the plant. Hydrogen produced for export must also include the cost of transportation to the closest of a select number of ports. The hydrogen transportation is assumed by the cheapest of three options

(pipeline, road or rail) based on the levelized cost over the lifetime of the plant.

Many of these calculations depend not only on the size of the plant, but also on the proximity of local infrastructure and the quality of the available energy sources. The details of these considerations, which vary depending on the plant's location, are described in the following section.

\section{Regional Calculation}

While the economic model outlined in the previous section provides an estimate of the cost of hydrogen production at a single location, a distinguishing feature of the Bluecap model is its ability to estimate the regional economic potential for particular types of projects. These regional calculations are performed by combining the plant's cash flow model with maps of the capacity factor of the associated power supply, the distance to infrastructure and transportation distance.

To do so, the net present value of the hydrogen plant is first calculated as a function of the capacity factor of the underlying power-supply, ignoring 
the infrastructure costs. This function is then applied to the map of plant capacity factors. Next the net present cost of each infrastructure component is calculated and subtracted from the net present value map. This allows the code to conduct regional analysis in a matter of seconds - helping to enable rapid regional scenario modelling and large-scale infrastructure planning.

The solar capacity factor maps used for the figures shown in this paper are determined from an empirical method based on the average solar exposure. Capacity factors from existing solar plants are matched against their total average irradiance determined by the Bureau of Meteorology. This relationship is then used to generate a map of solar capacity factors. User-generated capacity factor maps may be employed instead if required. Additional restrictions are placed on CSP plants, which require a minimum level of irradiance for successful operation. For example, the International Renewable Energy Agency (IRENA) (2012), Krarti (2018) and Wang (2019), suggest that a minimum 1,600-2,000 $\mathrm{kWh}$ per square metre of annual direct normal irradiance exposure is required to ensure functioning CSP power systems. As such, we limit the use of CSP to regions with greater than 2,000 kWh exposure per square metre. The resulting capacity maps for photovoltaic plants and CSP plants are shown in Figure 2a and Figure 2b.

Wind capacity factors are a function of both the available resource and the type of turbine (the hub-height and turbine model). To this end, turbine manufacturers release power-wind speed curves that relate the output of the turbine to the speed of the prevailing winds. This data can be used to determine the expected output when combined with the wind speed distribution at a given location. While individual power-wind speed curves for specific turbines can be used to generate capacity factors for those turbines, in practice no single turbine is optimal for all wind conditions or locations. To account for the range of turbine specifications, we estimate the capacity factor using a bounding curve that encompasses the power-wind speed relationship of 57 different turbines (illustrated in Figure 3). These power-wind speed relationships were taken from the wind turbine library maintained at the Open Energy Platform (Open Energy Platform, 2020). For the present calculation, only turbines with a maximum capacity of 3,600 MW or less were considered to match the maximum capacity of typical onshore windfarms in Australia.

Local average wind speed distributions are determined from a $5 \mathrm{~km}$ resolution mesoscale wind atlas for Australia produced by Garrad Hassan Pacific Pty Ltd (2015). The variation in the wind speed is determined by 
taking the local standard deviation of wind speeds given in the MERRA2.0 database (Global Modeling and Assimilation Office, 2015a), normalized by the average wind speed. From this data, local distributions in the wind speed are modelled as Weibull functions with the same mean and scaled standard deviation. The local wind speed capacity is then estimated from this data and the bounding power-wind speed relationship for the turbines. The resulting map is show in Figure 2c.

a)
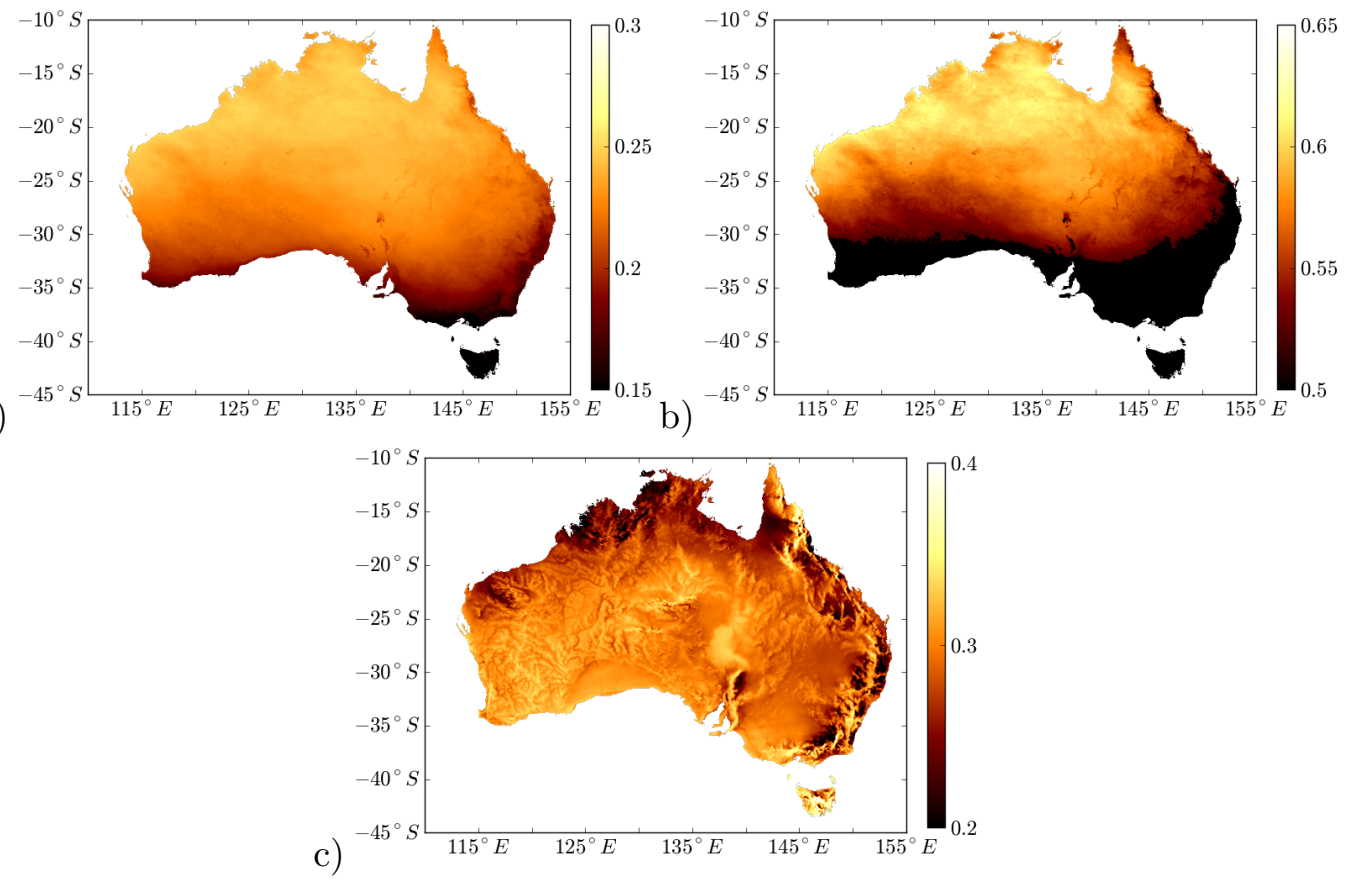

Figure 2: Capacity-factor maps for a) Photovoltaic solar; b) Concentrated solar power; and c) Wind power (150m hub-height). Note differences in scale between plots.

Hybrid power plants that combine wind and solar sources are also considered in the model. For these resources, we fix the ratio of wind and solar to the nameplate capacity of the plant as a whole. Next from the MERRA2 datasets for hourly wind speed and solar exposure (Global Modeling and Assimilation Office, 2015a,b), we calculate the hourly output from each power source as a fraction of their total capacity. In so doing, we must decide on the amount of curtailed energy. Rather than adopt a fixed curtailment rate (for example as done in Bloomberg New Energy Finance, 2020), instead we assume that the larger of the power plants is scaled to meet the energy 

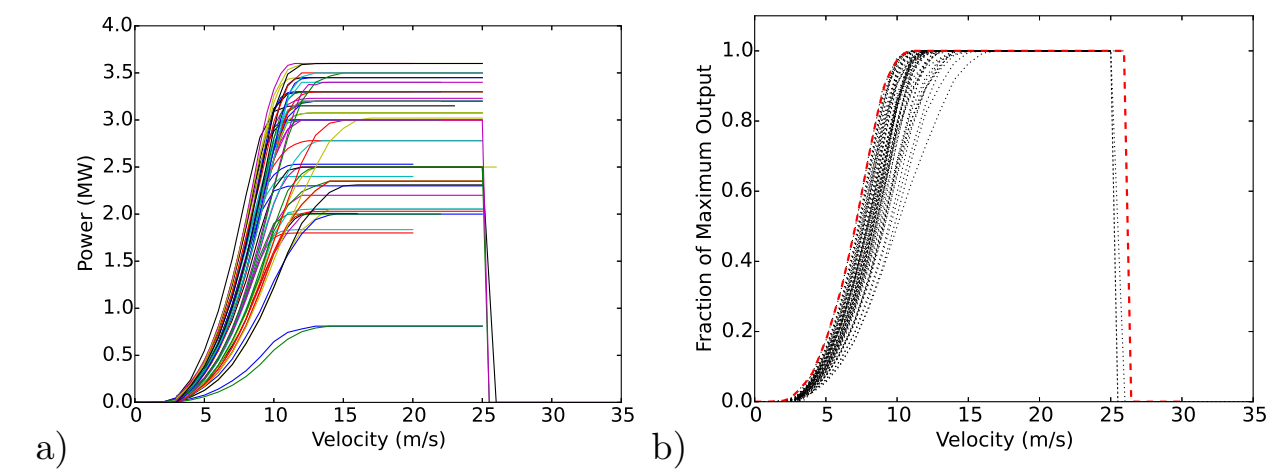

Figure 3: Wind capacity factors are determined using a bounding power-wind speed curve: a) Published power profiles of 57 turbines based on data from Open Energy Platform (2020); b) The profiles are scaled between 0 and 1 and the bounding curve (red dashed line) is used in conjunction with the wind speed distribution to estimate the regional capacity factors.

demands of hydrogen production when running at maximum capacity. However, the power plant will run below this capacity much of the time. When it does so, its power will be supplemented by the output from the second power station. Excess energy produced when the combined output exceeds the hydrogen plant's maximum capacity is assumed to be curtailed.

We also include an assessment of hydrogen production from non-renewable resources, namely coal-gasification and steam-methane reformation from natural gas. These projects involve separate considerations to those employed in the renewable energy calculation. For these models, we again assume that the hydrogen plant may be located at any point within Australia, but that a supply of coal or gas is required to operate. For steam-methane reformation, we assume that gas is supplied from any of the existing major gas pipelines around Australia (Geoscience Australia, 2014; OpenStreetMap contributors, 2018; WAPPIPE, 2020). For coal-gasification, we assume that the coal is transported by truck from an existing coal mine (based on data in Hughes, 2019) to the hydrogen plant. The locations of the mines and pipelines considered in the model are shown in Figure 4.

For steam-methane-reformation projects, gas-pipeline connection costs are determined based on the distance from the hydrogen plant location to the closest gas-pipeline. We assume that gas is supplied to the plant with standard 8-inch pipelines, using costs based on those provided by the Core Energy Group (2015). The cost of hydrogen-production for the steam-methane- 


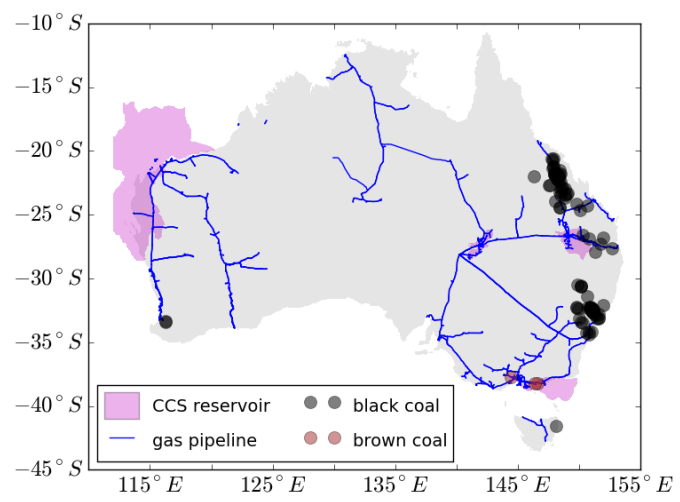

Figure 4: Locations of carbon sequestration reservoirs, gas pipelines and mines considered when determining hydrogen production from nonrenewable sources.

reformation plant is based on estimates given in the CSIRO Hydrogen Roadmap (Bruce et al., 2018). Coal for coal-gasification is likewise assumed to be sourced from currently-operating black-or-brown coal mines from around Australia. The cost of coal transportation is based on the distance traveled, the fleet costs and the mass transported using estimates in the AusIMM mine cost estimation handbook (Burt et al., 2012) adjusted to present-day prices (Australian Bureau of Statistics, 2020).

Both steam-methane reformation and coal gasification produce carbon dioxide that must be sequestered for the production of blue hydrogen. Based on work conducted under the National Carbon Mapping and Infrastructure Plan (Carbon Storage Taskforce, 2009), Geoscience Australia has identified several potential reservoirs at an advanced stage of development for long-term CO2 sequestration (Feitz et al., 2019). Again, while the CSIRO Hydrogen Roadmap (Bruce et al., 2018) includes the costs of sequestration in its estimates, it does not account for the transmission cost. Instead, these expenses are represented using a model of CO2-transmission costs developed for the Australian market (Wiley et al., 2015). The transmission-cost model requires an estimate of the amount of $\mathrm{CO} 2$ that must be sequestered at the site. The amount of carbon dioxide sequestered depends on the type of plant and the mass of hydrogen produced.

For steam-methane reformation, the equations governing hydrogen production can be summarized as a steam-methane reforming reaction:

$$
\mathrm{CH}_{4}+\mathrm{H}_{2} \mathrm{O} \rightarrow \mathrm{CO}+3 \mathrm{H}_{2},
$$


followed by a water-gas shift reaction:

$$
\mathrm{CO}+\mathrm{H}_{2} \mathrm{O} \rightarrow \mathrm{CO}_{2}+\mathrm{H}_{2},
$$

i.e. four molecules of hydrogen $\left(\mathrm{H}_{2}\right)$ are produced for each molecule of carbon dioxide. This amounts to approximately $5.5 \mathrm{~kg} \mathrm{CO} / \mathrm{kg} \mathrm{H}$. However, rates of $10-11 \mathrm{~kg} \mathrm{CO} / \mathrm{kg} \mathrm{H}$ may be more typical of real systems due to process inefficiencies (Bruce et al., 2018).

Production of hydrogen from coal may be approximated by the following (unbalanced) coal gasification reaction:

$$
\mathrm{CH}_{0.8}+\mathrm{O}_{2}+\mathrm{H}_{2} \mathrm{O} \rightarrow \mathrm{H}_{2}+\mathrm{CO}_{2}+\mathrm{CO} .
$$

Carbon monoxide produced in this reaction can then be employed in a watergas shift reaction as above (Tidball and Knoke, 2009). In practice, different sources of coal contain different proportions of hydrogen and carbon, as well as additional elements such as sulfur, nitrogen, and oxygen. Likewise, process inefficiencies will again affect conversion ratios. National Renewable Energy Laboratory (NREL) assessments of hydrogen production that account for reaction thermodynamics and multiple chemical species estimate a ratio of approximately 22-25 $\mathrm{kg} \mathrm{CO} / 2 / \mathrm{kg} \mathrm{H}$ (Steward et al., 2008), while estimated $\mathrm{CO}_{2}$ outputs from industrial trial-facilities are substantially higher (e.g. HESC Project Partners, 2019). Accordingly, we provide the user with the ability to set both the amount of $\mathrm{CO}_{2}$ produced and fuel consumed per kilogram of hydrogen generated.

Additional infrastructure (e.g. water, power and transportation) is required to support the production of hydrogen. The nature of this infrastructure depends on the form of the plant and the intended market for the produced hydrogen. These infrastructure costs are determined by combining cost models for each component (typically expressed as functions of the amount of hydrogen produced and the distance required) with maps of the distances to existing assets or transportation distances to export ports - for example, a) distance to the nearest water source (wastewater or seawater); b) pipeline distance to export ports; c) distance to road transportation; and d) distance to rail. Examples of such regional distance maps are shown in Figure 5 .

In particular, a water source is required for all hydrogen plants - although the amount will vary depending on the mode of production and as water may 

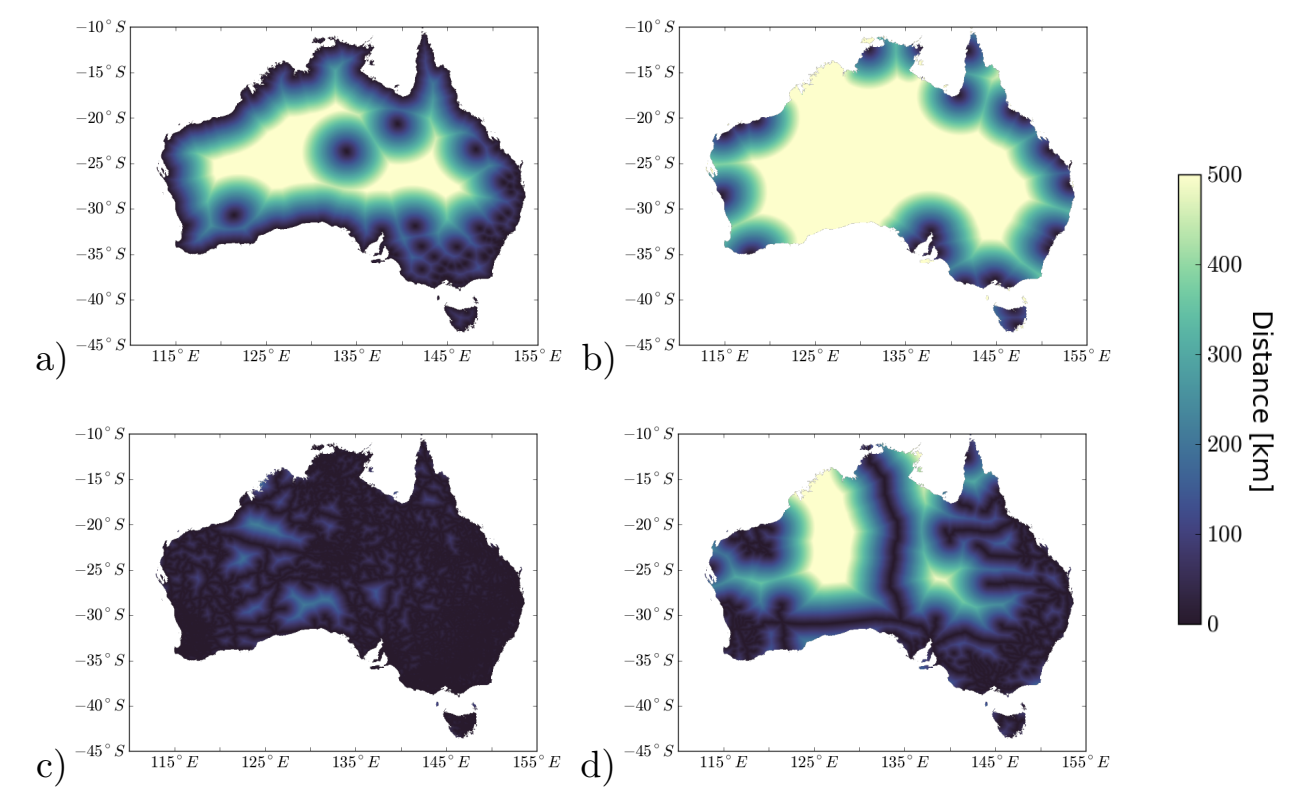

c)

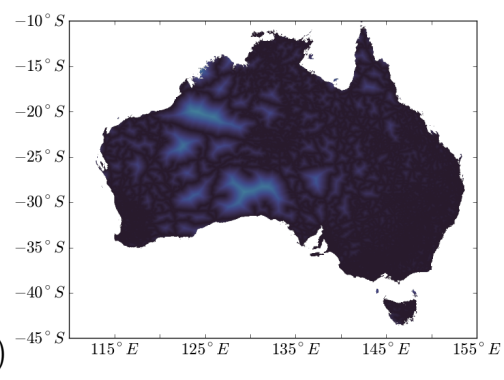

d)

Figure 5: Examples of infrastructure-distance maps: a) distance to the nearest water source (wastewater or seawater); b) pipeline distance to export ports; c) distance to road transportation; and d) distance to rail. Maps derived from Australian Bureau of Statistics (2016), ARUP (2019) and the Open Street-Maps database (OpenStreetMap contributors, 2018) 
be required for cooling. Water transmission costs are estimated from a linear fit of cost estimates for 54 pipelines (Miriam Vale Shire Council, 2007; Tonkin Science Engineering, 2011; Wise and Raft, 2013; Gao et al., 2016), as detailed in Walsh et al. (2020). It should be noted that there is considerable community concern in Australia over freshwater use for large-scale hydrogen production (National Hydrogen Strategy Taskforce, 2019b). Thus, water is assumed to be obtained from either seawater through desalination or from wastewater sources from high density urban areas or regional townships for large-scale hydrogen production (Feitz et al., 2019). Here, towns listed as having populations above 10,000 on the ABS 2016 UCL (urban center and localities) list are used as a proxy for high density urban areas with wastewater recycling facilities (Australian Bureau of Statistics, 2016).

Road or rail connections are required to construct each plant, and additional transportation costs may need to be accounted for if the hydrogen is intended for the export market. These road and rail infrastructure requirements and transportation distances are determined from the Open StreetMaps database (OpenStreetMap contributors, 2018). The maps are used to calculate both the distance to the closest road or rail line and the shortest route to the nearest export port. Not all ports will be suited to hydrogen export due to the need for a liquid berth, as well as minimum channel and berth specifications. Thus we base our list of export locations on the ports compiled in the Australian Hydrogen Hubs Study (ARUP, 2019). Transport infrastructure costs (road and rail connections) are determined from those given in the AusIMM cost estimation handbook (Burt et al., 2012), while ongoing costs are taken from the estimates in the CSIRO Roadmap (Bruce et al., 2018). Pipeline transmission costs are based on estimates in Kan and Shibata (2018) for hydrogen pipeline transmission in Australia, which include both capital and ongoing cost-estimates. At each point in the regional calculation, we determine the net present cost of each transportation option and select the method that results in the minimum overall net present cost.

\section{Case studies}

In this section, we present the results of example assessments generated by the Bluecap model. The Hydrogen Economic Fairways Tool is used to

estimate the potential for hydrogen production from large scale solar and wind farms, steam-methane reformation and coal production. 
The first case study considers the economic potential of hydrogen production from a large-scale photovoltaic solar facility. For this study, we consider

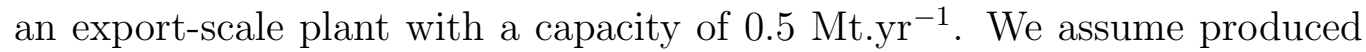
hydrogen is sold at the export port for a price of $\$ 5.50 \mathrm{AUD} / \mathrm{kg} \mathrm{H} \mathrm{H}_{2}$. Results are shown in Figure 6, which presents the regional NPV for this particular project. Nevertheless, it should be noted that the absolute NPV is sensitive to the assumed export price which is somewhat speculative. Instead, we focus on the relative value of each region by mapping the percentile ranking of each location in Figure 7a.

The results in both Figure 6 and Figure 7a suggest significant prospects for the development of such a facility in the northern states and territories, as well as the central southern parts of the mainland (in the state of South Australia). It should be noted that many of these areas also rank highly for development of CSP projects (Figure 7b). It is evident from the earlier capacity maps given in Figure $2 \mathrm{a}$ and $\mathrm{b}$, that these regions benefit from excellent solar resources. However, it is also clear that the high cost of hydrogen transmission is influential in determining which locations are best suited for hydrogen production. Proximity to export ports and ready access to transportation infrastructure are also key factors in determining regional rankings.

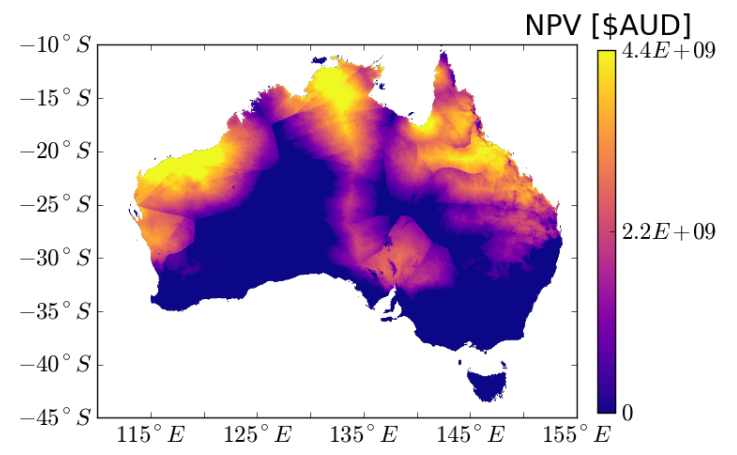

Figure 6: Predicted regional NPV for a large-scale solar-powered hydrogen plant.

Next we consider the economic fairways for hydrogen and wind development. Sites appropriate for large-scale production of renewable energy from wind are found in all states. However, only a few are located close to transportation routes and export ports. In addition, as illustrated in Figure 2c, wind speeds show greater spatial variation compared to solar irradiance. As 


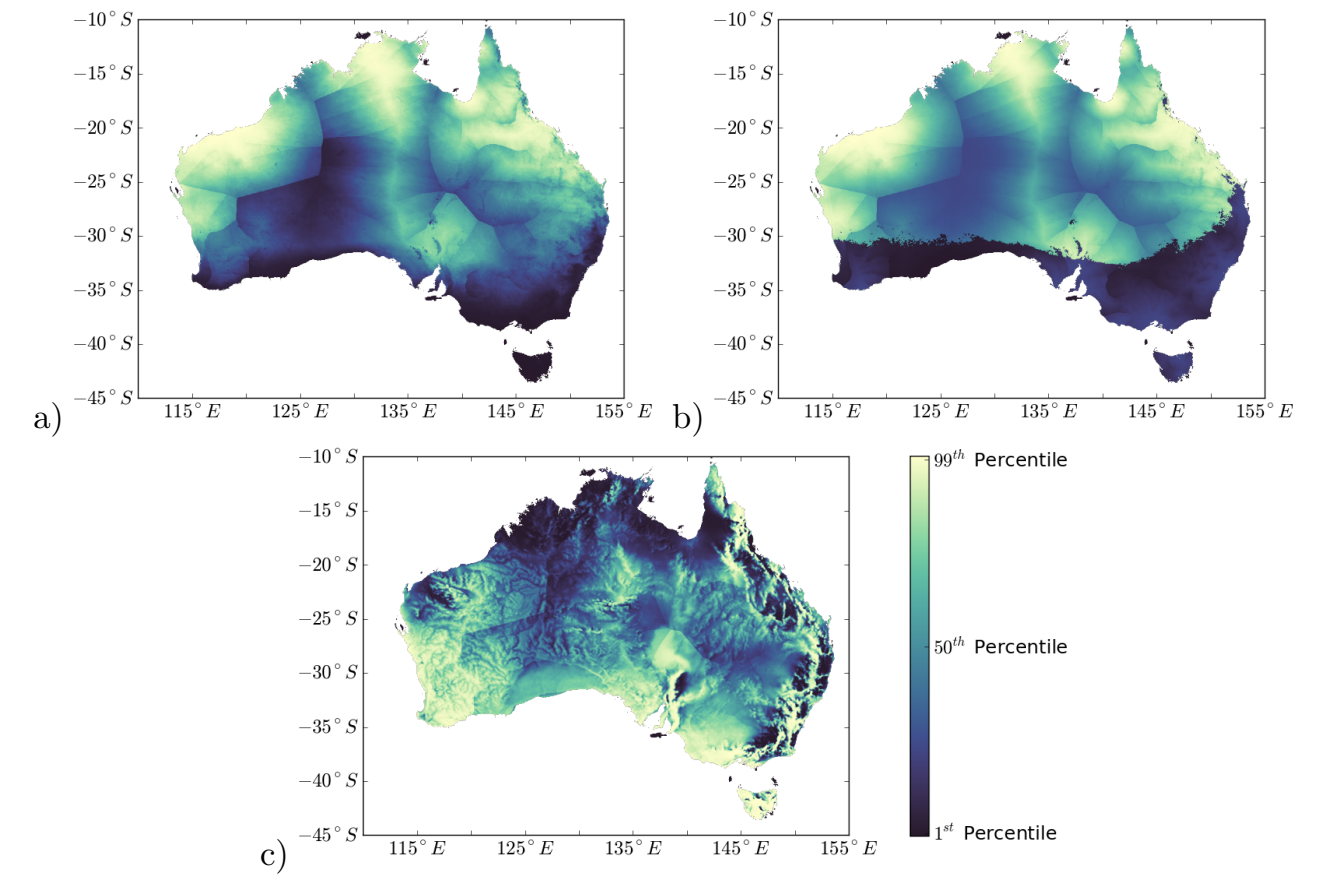

Figure 7: Regional percentile-rankings ( $0 \%$ worst, $100 \%$ best) for hydrogen production from renewable resources: a) Photovoltaic solar power; b) CSP; and c) Wind power. 
a result the economic fairways for hydrogen produced from wind power are sparser and more widely distributed. Nevertheless, there are notable pockets of high potential for wind production in north-eastern Australia, and across the southern parts of the mainland and Tasmania. It should be noted that under the present model, wind power typically has a higher break-even hydrogen price (i.e. the minimum price required to achieve a positive NPV) than solar-powered projects - particularly for large-scale operations. Although wind power benefits from higher capacity factors, the economies of scale disadvantage wind production over solar developments. While there appear to be economic advantages to larger solar plants, the reported cost of wind farms changes little per unit capacity as a function of the scale of the operation (perhaps due to the discrete nature of individual turbine installation). Nevertheless, there are other reasons to consider hydrogen production in conjunction with wind power - for example as a means of energy storage or as an alternative revenue stream to offset periods of low electricity prices.

a)
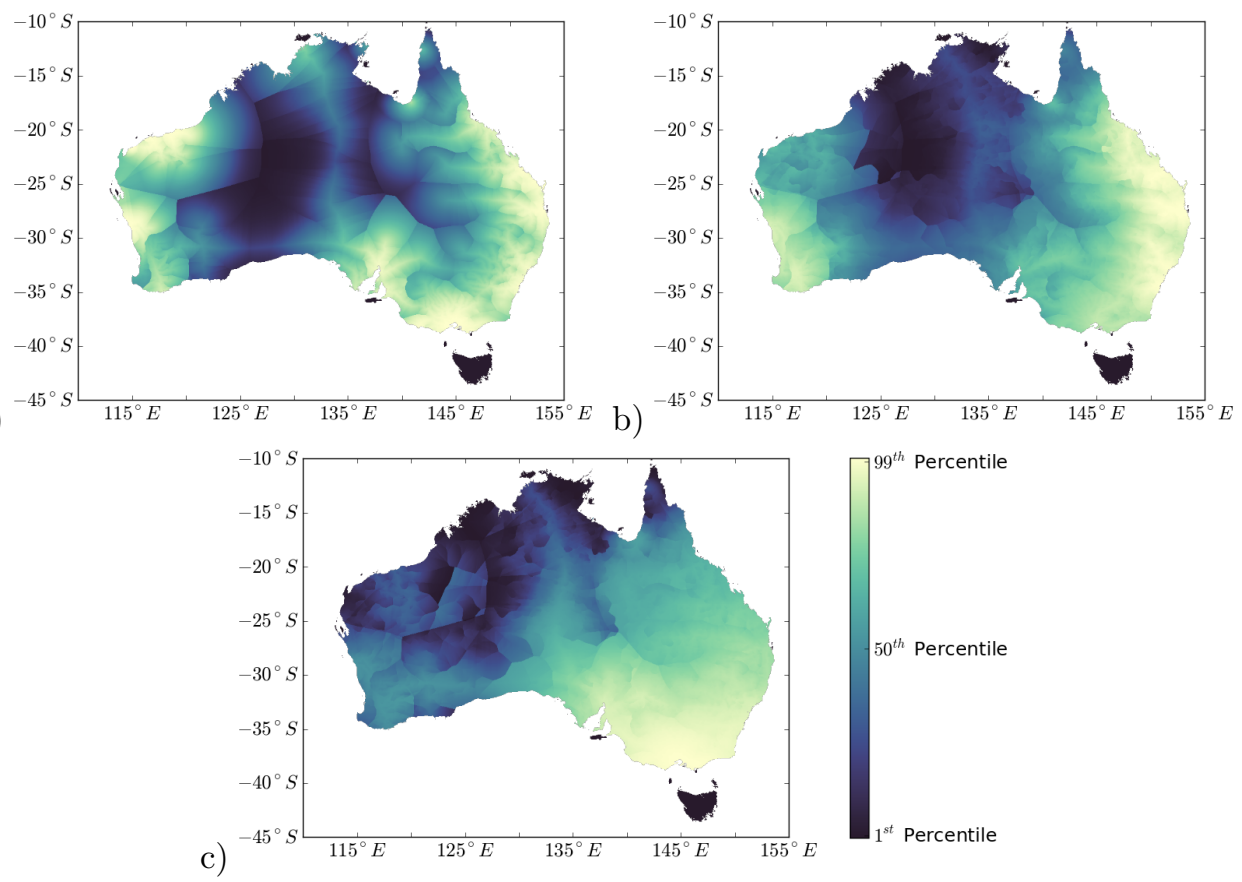

Figure 8: Regional percentile-rankings ( $0 \%$ worst, $100 \%$ best) for hydrogen production from non-renewable resources with carbon capture and storage: a) Steam-methane reformation; b) Black-coal gasification; and c) Brown-coal gasification.

In Figure 8, we consider the results of the economic fairways analysis for 
blue hydrogen production. The figures show the results for steam-methane reformation (Figure 8a) and black and brown coal-gasification projects combined with carbon capture and storage (Figures $8 \mathrm{~b} \& \mathrm{c}$ ).

The economics of hydrogen production from steam-methane reformation are dictated by the existing gas infrastructure and proximity to likely carbon capture and storage locations. North-western Western Australia is again highlighted as a particularly prospective region for hydrogen production. The existing ports and transportation infrastructure supporting gas production, and the close proximity of potential $\mathrm{CO}_{2}$ storage sites make the region an extremely attractive location for large-scale hydrogen production.

Similarly for black and brown coal mines, the proximity of a carbon storage reservoir is a key factor in determining the greatest prospectivity for hydrogen production. Existing coal mines are already serviced by roads and are in many cases relatively close to port. However, due to the amount of $\mathrm{CO}_{2}$ produced, the costs of sequestration are comparable to the costs of hydrogen transportation. The distance to sequestration sites in advanced stages of development currently inhibits competitive hydrogen production from black-coal mining in south western Australia (Figure 9b), while favouring production in the east that lie closer to $\mathrm{CO}_{2}$ storage basins.

The maps presented in Figure 9 show the spatial distribution of the regions predicted to be in the upper $95^{\text {th }}$ percentile for each form of hydrogen production. Figure 9a shows those regions most favourable to hydrogen production from renewable sources, while Figure $9 \mathrm{~b}$ presents the equivalent for non-renewable sources combined with carbon capture and storage. Direct comparisons between projected values for different resources should be treated with caution, due to the uncertainties associated with cost estimation for each project type. Nevertheless, the Bluecap model can be used to identify areas with high potential for success from not just one, but a number of different production methods. This is important from the perspective of infrastructure planning. At the most basic level, export, transmission and storage facilities should be located close to regions best able to take advantage of multiple potential hydrogen suppliers. Moreover, identifying regions with high potential for multiple production methods is also necessary under bridging scenarios, in which non-renewable sources initiate industry development and establish trading pipelines, while technological developments make prices for renewable/green hydrogen more competitive. 

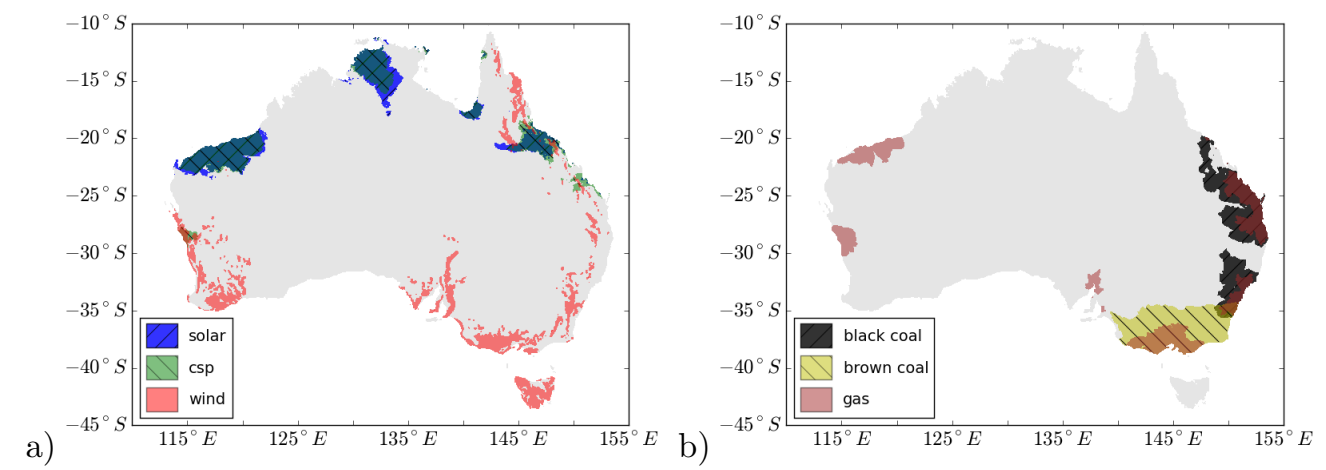

Figure 9: Regions ranked in the $95^{t h}$ percentile for different categories of hydrogen production from (a) renewable sources and (b) non-renewable sources with carbon capture and storage.

\section{Conclusion}

Hydrogen provides a potential solution to the problems of decarbonizing large-scale transportation, steel and cement production, and industrial heat. It also offers benefits in the form of energy security and grid stability. However, producing a new energy supply of a similar magnitude to existing energy pipelines will involve a monumental engineering effort.

Successful hydrogen development will require a combination of factors: sufficient energy and water resources, proximity to markets, as well as supporting infrastructure. Identifying locations with a concentration of these factors will help governments to direct funding and plan infrastructure to better support the nascent industry, as well as recognise opportunities for investors.

Here, we have presented one such tool for determining the economic fairways for hydrogen production, i.e. those regions favoured to succeed from an economic perspective. The tool assesses regional economic potential by combining economic models of hydrogen production with regional assessments of resource potential and access to infrastructure. Its rapid analysis enables scenario testing, helping to prioritize future research and investment. In so doing, it provides a novel platform to highlight areas of strategic importance for hydrogen project development for the benefit of industry, government and the community. 


\section{Acknowledgements}

We gratefully acknowledge the support for this project provided under Geoscience Australia's Exploring for the Future program. We also thank Marcus Haynes for his guidance on implementing the Hydrogen Economic Fairways tool's user interface, creating a publicly accessible platform for user's to interact with the Bluecap code. We also acknowledge the support provided by individuals, industry groups and government organisations which enabled this work. L. Easton, J. Moloney and A. Feitz publish with the permission of the CEO of Geoscience Australia.

\section{References}

ARUP, 2019. Australian Hydrogen Hubs Study: Technical Study. Technical Report. COAG Energy Council Hydrogen Working Group.

Australian Bureau of Statistics, 2016. 1270.0.55.004 - Australian Statistical Geography Standard, Volume 4 - Significant Urban Areas, Urban Centres and Localities.

Australian Bureau of Statistics, 2020. Cat. No. 6427.0 - Producer Price Indexes, Australia, Sep 2020. Table 11. Input to the Coal mining industry, index numbers and percentage changes .

Ball, M., Wietschel, M., 2009. The future of hydrogen-opportunities and challenges. International Journal of Hydrogen Energy 34, 615-627.

Bataille, C., Åhman, M., Neuhoff, K., Nilsson, L.J., Fischedick, M., Lechtenböhmer, S., Solano-Rodriquez, B., Denis-Ryan, A., Stiebert, S., Waisman, H., et al., 2018. A review of technology and policy deep decarbonization pathway options for making energy-intensive industry production consistent with the paris agreement. Journal of Cleaner Production 187, 960-973.

Bennoua, S., Le Duigou, A., Quéméré, M.M., Dautremont, S., 2015. Role of hydrogen in resolving electricity grid issues. International Journal of Hydrogen Energy 40, 7231-7245.

Bloomberg New Energy Finance, 2020. Hydrogen - the economics of production from renewables, full report. Technical Report. Bloomberg. 
Bruce, S., Temminghoff, M., Hayward, J., Schmidt, E., Munnings, C., Palfreyman, D., Hartley, P., 2018. National hydrogen roadmap. Australia: CSIRO .

Burt, K., Lockyer, C., McShane, K., Fong, O.T. (Eds.), 2012. Cost estimation handbook, Second Edition, Monograph 27. Australasian Inst. of Mining and Metallurgy.

Carbon Storage Taskforce, 2009. National Carbon Mapping and Infrastructure Plan-Australia: Full Report. Technical Report. Department of Resources Energy and Tourism, Canberra.

Core Energy Group, 2015. Gas Production and Transmission Costs Eastern and South Eastern Australia. Technical Report. Core Energy Group.

Feitz, A.J., Coghlan, R., Tenthorey, E., 2019. Prospective Hydrogen Production Regions of Australia. Technical Report. Geoscience Australia.

Friedmann, S.J., Fan, Z., Tang, K., 2019. Low-carbon heat solutions for heavy industry: sources, options, and costs today. Columbia University Center on Global Energy Policy .

Gao, L., Hou, C., Chen, Y., Barrett, D., Mallants, D., Li, W., Liu, R., 2016. Potential for mine water sharing to reduce unregulated discharge. Journal of Cleaner Production 131, 133-144.

Garrad Hassan Pacific Pty Ltd, 2015. DNV-GL Wind speed at 150m, in: AREMI National Map portal.

Geoscience Australia, 2014. National onshore gas pipelines database.

Geoscience Australia, 2021. AusH2 - Australia's Hydrogen Opportunities Tool (AusH2.ga.gov.au). URL: AusH2.ga.gov .au.

Global Modeling and Assimilation Office, 2015a. MERRA-2 inst1_2d_asm_Nx: 2d,1-Hourly, Instantaneous, Single-Level, Assimilation, Single-Level Diagnostics V5.12.4 doi:10.5067/3Z173KIE2TPD.

Global Modeling and Assimilation Office, 2015b. MERRA2 tavg1_2d_rad_Nx: 2d,1-Hourly, Time-Averaged,SingleLevel,Assimilation, Radiation Diagnostics

V5.12.4 doi:10.5067/Q9QMY5PBNV1T. 
Gutiérrez-Martín, F., Guerrero-Hernández, I., 2012. Balancing the grid loads by large scale integration of hydrogen technologies: The case of the spanish power system. International journal of hydrogen energy 37, 1151-1161.

Haynes, M., Walsh, S., Czarnota, K., Northey, S., Yellishetty, M., 2020. Economic fairways assessments across northern Australia. Exploring for the Future: extended abstracts, Geoscience Australia, Canberra , 1-4.

HESC Project Partners, 2019. Submission to National Hydrogen Strategy Taskforce: HESC case study.

Hinkley, J., Hayward, J., McNaughton, R., Gillespie, R., Matsumoto, A., Watt, M., Lovegrove, K., 2016. Cost assessment of hydrogen production from PV and electrolysis. Report to ARENA as part of Solar Fuels Roadmap, Project A-3018, 1-4.

Hughes, A., 2019. Australian Operating Mines Map. Technical Report. Geoscience Australia.

International Energy Agency (IEA), 2019. The Future of Hydrogen: Seizing Today's Opportunities. Technical Report. International Energy Agency.

International Renewable Energy Agency (IRENA), 2012. Renewable energy technologies: Cost analysis series. Technical Report.

Kan, S., Shibata, Y., 2018. Evaluation of the economics of renewable hydrogen supply in the apec region, in: 34th Conference on Energy, Economy, and Environment, Japan Society of Energy and Resources (JSER).

Kato, E., Kurosawa, A., 2019. Evaluation of Japanese energy system toward 2050 with TIMES-Japan-deep decarbonization pathways. Energy Procedia $158,4141-4146$.

Krarti, M., 2018. Optimal design and retrofit of energy efficient buildings, communities, and urban centers. Butterworth-Heinemann.

Lovegrove, K., Bader, R., Fernandez, D., Urkalan, K., 2018. Concentrating Solar Thermal Technology Status - Informing A CSP Road Map for Australia. Technical Report. Turner, ACT, Australia. 
Miriam Vale Shire Council, 2007. Engineering estimates and financial implication of pipeline and desalination options for Agnes water and 1770 . Technical Report. Prepared by Burns Bridge Transactions.

National Hydrogen Strategy Taskforce, 2019a. National hydrogen industry - Issues paper series - Developing a hydrogen export industry. Technical Report. Department of Industry, Innovation and Science.

National Hydrogen Strategy Taskforce, 2019b. National hydrogen industry - Issues paper series - Understanding community concerns for safety and the environment. Technical Report. Department of Industry, Innovation and Science.

Open Energy Platform, 2020. Wind turbine library. URL: https://openenergy-platform.org/dataedit/view/supply/wind_turbine_library.

OpenStreetMap contributors, 2018. Planet data retrieved from https://planet.osm.org, 2018. https://www.openstreetmap.org .

Ren, J., Andreasen, K.P., Sovacool, B.K., 2014. Viability of hydrogen pathways that enhance energy security: a comparison of China and Denmark. International journal of hydrogen energy 39, 15320-15329.

Scita, R., Raimondi, P.P., Noussan, M., 2020. Green Hydrogen: the Holy Grail of Decarbonisation? An Analysis of the Technical and Geopolitical Implications of the Future Hydrogen Economy. Fondazione Eni Enrico Mattei Working Papers .

Steward, D., Ramsden, T., Zuboy, J., 2008. H2A production model, version 2 user guide. Technical Report. National Renewable Energy Lab.(NREL), Golden, CO (United States).

Tidball, R., Knoke, S., 2009. Hydrogen and Our Energy Future. Technical Report. US Department of Energy Hydrogen Program. doi:10.2172/950018.

Tonkin Science Engineering, 2011. Pipeline to the Sea, Feasibility Study Phase 1. Technical Report. Murray-Darling Basin Authority.

US DOE, 2002. A National Vision of America's Transition to a Hydrogen Economy - To 2030 and Beyond. Technical Report. US DOE. 
Walsh, S.D., Northey, S.A., Huston, D., Yellishetty, M., Czarnota, K., 2020. Bluecap: A geospatial model to assess regional economic-viability for mineral resource development. Resources Policy 66, 101598.

Wang, Z., 2019. General design of a solar thermal power plant, in: Wang, Z. (Ed.), Design of Solar Thermal Power Plants. Academic Press, pp. 117 224. doi:https://doi.org/10.1016/B978-0-12-815613-1.00003-1.

WAPPIPE, 2020. Western Australian Petroleum Pipelines. Technical Report. Government of Western Australia Department of Mines, Industry Regulation and Safety.

Wiley, D., Neal, P., Ho, M., Fimbres Weihs, G., 2015. Carbon dioxide transport and storage, in: Australian Power Generation Technology Report. Electric Power Research Institute, Inc., pp. 179-201.

Wise, N., Raft, S., 2013. Final Report, Pipeline NSW Program. Technical Report. NSW Office of Water, Department of Primary Industry NSW. 